\title{
Oral beraprost sodium improves exercise capacity and ventilatory efficiency in patients with primary or thromboembolic pulmonary hypertension
}

\author{
N Nagaya, Y Shimizu, T Satoh, H Oya, M Uematsu, S Kyotani, F Sakamaki, N Sato, \\ N Nakanishi, K Miyatake
}

See end of article for authors' affiliations

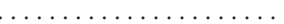

Correspondence to: Dr Noritoshi Nagaya, Division of Cardiology, Department of Medicine, National Cardiovascular Centre, 5-7-1 Fujishirodai Suita, Osaka 565-8565, Japan;

nagayann@hsp.ncvc.go.jp

Accepted

20 December 2001

\begin{abstract}
Objective: To investigate the effect of beraprost sodium, an orally active prostacyclin analogue, on exercise capacity and ventilatory efficiency in patients with primary pulmonary hypertension and chronic thromboembolic pulmonary hypertension.

Patients and design: Symptom limited cardiopulmonary exercise testing was performed before and 3 (1) months (mean (SEM)) after beraprost treatment in 30 patients with precapillary pulmonary hypertension (14 with primary pulmonary hypertension and 16 with chronic thromboembolic pulmonary hypertension).

Results: Long term treatment with beraprost resulted in significant increases (mean (SEM)) in peak workload (87 (4) W to 97 (5) W, p $<0.001$ ) and peak oxygen consumption (peak $\dot{V}_{O_{2}}, 14.9$ (0.7) $\mathrm{ml} / \mathrm{kg} / \mathrm{min}$ to $16.8(0.7) \mathrm{ml} / \mathrm{kg} / \mathrm{min}, \mathrm{p}<0.001)$. Beraprost decreased the ventilatory response to carbon dioxide production during exercise $\left(\dot{V}_{E}-\dot{V}_{\mathrm{CO}_{2}}\right.$ slope, $42(2)$ to $\left.37(1), p<0.001\right)$. No significant difference in the responses of these variables to beraprost treatment was observed between patients with primary pulmonary hypertension and chronic thromboembolic pulmonary hypertension.

Conclusions: Oral administration of beraprost sodium may improve exercise capacity and ventilatory efficiency in patients with both primary and chronic thromboembolic pulmonary hypertension.
\end{abstract}

$M$ ost patients with primary pulmonary hypertension or chronic thromboembolic pulmonary hypertension have severe exertional limitation from the early phase of the disease, which ultimately progresses to right ventricular failure and death. ${ }^{1-3}$ The severely reduced exercise capacity is attributed to an impaired vasodilator response of the pulmonary arteries during exercise. ${ }^{4}$ Earlier studies have shown that a continuous intravenous infusion of epoprostenol (prostacyclin) ameliorates pulmonary hypertension and improves exercise capacity in patients with primary pulmonary hypertension..$^{5-8}$ This treatment, however, requires a continuous infusion device and so is more uncomfortable and expensive than oral drug treatment. In contrast to major vessel chronic thromboembolic pulmonary hypertension, which may be surgically corrected, ${ }^{9}$ peripheral vessel thromboembolic pulmonary hypertension cannot be treated surgically and so an alternative therapeutic approach is necessary.

Beraprost sodium is a newly developed prostacyclin analogue with a stable structure because of its cyclopentabenzofuranyl skeleton. ${ }^{10}$ Unlike epoprostenol, beraprost has prolonged activity in the body and so can be taken by mouth. It is similar to epoprostenol, however, in that it produces strong vasodilatation and inhibits platelet aggregation. ${ }^{11}$ Recently, we and others have shown that beraprost reduces pulmonary vascular resistance in patients with primary pulmonary hypertension, ${ }^{12-14}$ but it is not yet known whether oral administration of this agent improves exercise capacity and ventilation in such patients. Furthermore, there are few data on the effects of beraprost in patients with chronic thromboembolic pulmonary hypertension.

Cardiopulmonary exercise testing allows reproducible assessment of functional capacity and treatment efficacy in patients with pulmonary hypertension. ${ }^{15-17}$ In the present study we therefore investigated the effects of long term treatment with beraprost on exercise capacity and ventilatory efficiency using peak oxygen consumption (peak $\dot{\mathrm{V}}_{2}$ ) and the ventilatory response to carbon dioxide production $\left(\dot{\mathrm{V}}_{\mathrm{E}}-\dot{\mathrm{V}}_{\mathrm{CO}_{2}}\right.$ slope $)^{17-19}$ in patients with primary and chronic thromboembolic pulmonary hypertension.

\section{METHODS}

\section{Study patients}

Thirty two patients with precapillary pulmonary hypertension (mean pulmonary arterial pressure $\geqslant 25 \mathrm{~mm} \mathrm{Hg}$ ) and who were suitable for a maximum cardiopulmonary exercise test, as judged by the attending physicians, were enrolled in the study. Patients in New York Heart Association (NYHA) functional class IV were excluded. Two patients were not retested because they were referred to local institutions. Thus the remaining 30 patients with precapillary pulmonary hypertension (14 with primary pulmonary hypertension and 16 with chronic thromboembolic pulmonary hypertension) were studied.

All patients were thoroughly investigated to identify the cause of their pulmonary hypertension. Investigations included chest radiography, lung scanning, pulmonary function tests, Doppler echocardiography, and cardiac catheterisation, according to the protocol of the National Institutes of Health registry on primary pulmonary hypertension. ${ }^{1}$ The diagnosis of chronic thromboembolic pulmonary hypertension was confirmed by pulmonary angiography. 20

Demographic, haemodynamic, and pulmonary function data at baseline are shown in table 1 . Seven patients with milder forms of pulmonary hypertension (mean (SD) pulmonary arterial pressure 32 (3) $\mathrm{mm} \mathrm{Hg}$; one with primary

Abbreviations: NYHA, New York Heart Association; $\dot{\mathrm{V}} \mathrm{E}-\dot{\mathrm{V}}_{\mathrm{CO}_{2}}$ slope, ventilatory response to carbon dioxide production; $\dot{V}_{O_{2}}$, oxygen consumption; $\Delta \mathrm{VO}_{2} / \Delta \mathrm{W}$, ratio of change in oxygen uptake to change in work rate 
Table 1 Baseline characteristics of patients with primary pulmonary hypertension and chronic thromboembolic pulmonary hypertension

\begin{tabular}{|c|c|c|c|}
\hline Variables & All patients $(n=30)$ & $\mathrm{PPH}(n=14)$ & CTEPH $(n=16)$ \\
\hline \multicolumn{4}{|l|}{ Demographics } \\
\hline Age (years) & $51(3)$ & $43(5)$ & $59(4)^{*}$ \\
\hline Male/female (n) & $10 / 20$ & $6 / 8$ & $4 / 12$ \\
\hline \multicolumn{4}{|l|}{ NYHA functional class (n) } \\
\hline$\|$ & 9 & 4 & 5 \\
\hline III & 21 & 10 & 11 \\
\hline \multicolumn{4}{|l|}{ Baseline haemodynamics } \\
\hline MPAP $(\mathrm{mm} \mathrm{Hg})$ & $42(3)$ & $48(3)$ & $37(4)^{*}$ \\
\hline $\mathrm{CO}\left(\mathrm{l} / \mathrm{min} / \mathrm{m}^{2}\right)$ & $3.7(0.2)$ & $3.7(0.4)$ & $3.8(0.4)$ \\
\hline PVR (Wood units) & $13.5(1.4)$ & $12.9(1.8)$ & $9.3(2.2)$ \\
\hline $\operatorname{RAP}(\mathrm{mm} \mathrm{Hg})$ & $5(1)$ & $4(1)$ & $5(1)$ \\
\hline PCWP $(\mathrm{mm} \mathrm{Hg})$ & $8(1)$ & 7 (1) & $9(1)$ \\
\hline \multicolumn{4}{|l|}{ Drug treatment $(n)$} \\
\hline Anticoagulant agents & 28 & 12 & 16 \\
\hline Digitalis & 9 & 4 & 5 \\
\hline Diuretics & 12 & 6 & 6 \\
\hline Calcium antagonists & 2 & 1 & 1 \\
\hline \multicolumn{4}{|c|}{$\begin{array}{l}\text { Data are mean (SEM) or } \mathrm{n} \text {. } \\
\text { * } \mathrm{p}<0.05 \mathrm{vPPH} \text {. } \\
\mathrm{CO} \text {, cardiac output; CTEPH, chronic thromboembolic pulmonary hypertension; MPAP, mean pulmonary } \\
\text { arterial pressure; NYHA, New York Heart Association; PCWP, pulmonary capillary wedge pressure; PPH, } \\
\text { primary pulmonary hypertension; PVR, pulmonary vascular resistance; RAP, mean right atrial pressure. }\end{array}$} \\
\hline
\end{tabular}

pulmonary hypertension and six with chronic thromboembolic pulmonary hypertension) were recruited-with their written informed consent-to test the reproducibility of the paired cardiopulmonary exercise tests.

The study was approved by the ethics committee of the National Cardiovascular Centre, and all patients gave written informed consent.

\section{Beraprost treatment}

The study was designed to maintain the beraprost treatment at the highest dose tolerated, as reported previously. ${ }^{14}$ In brief, oral administration of the drug was begun at 60 or $80 \mu \mathrm{g} / \mathrm{day}$ and increased in increments of 60 or $80 \mu \mathrm{g} /$ day over $1-2$ weeks to the highest dose tolerated (mean (SEM), 138 (14) $\mu$ g/day; range $60-360 \mu \mathrm{g} / \mathrm{day}$ ). The total daily dose was split into three or four separate doses. Side effects occurred in 16 patients (53\%) within a week of the administration of beraprost. These were: flushing in six patients, headache in four, flushing and headache in four, diarrhoea in one, and nausea in one. Further dose increments caused similar side effects in the remaining 14 patients, which limited the highest dose used. Clinically significant systemic hypotension or orthostatic hypotension was not observed in any patient. When intolerable side effects occurred, we either reduced the dose or gave the same daily dose in an increased number of smaller subdoses. All patients eventually tolerated a dose of at least $60 \mu \mathrm{g} /$ day. Treatment was continued for at least one month (mean (SEM) 3 (1) months, range 1-7 months) before the second exercise test was carried out. Additional treatment for pulmonary hypertension and right ventricular failure-such as anticoagulation, digitalis, and diuretics-was unchanged during the study. Because beraprost was the vasodilator of first choice in our institution, few patients were on calcium channel blockers.

\section{Haemodynamic studies}

Diagnostic right heart catheterisation was performed while the subjects were in a stable condition before starting treatment with beraprost. Haemodynamic variablesincluding mean pulmonary arterial pressure, mean right atrial pressure, and pulmonary capillary wedge pressure-were measured in all patients. Cardiac output was measured by Fick's method. Pulmonary vascular resistance was calculated by dividing mean pulmonary artery pressure by cardiac output.

\section{Cardiopulmonary exercise testing}

Cardiopulmonary exercise testing was undertaken before and during beraprost treatment. Paired cardiopulmonary exercise tests were also performed in a group of patients with less severe pulmonary hypertension who were not on beraprost treatment, to exclude training effects. The time interval from the baseline exercise test to the second exercise test was 3 (1) months in both groups (with and without beraprost treatment).

The patients performed exercise seated on a cycle ergometer. They first pedalled at $55 \mathrm{rpm}$ without any added load for one minute. The work rate was then increased by $15 \mathrm{~W} / \mathrm{min}$ up to their symptom limited maximum. Heart rate was monitored with standard electrocardiographic leads, and blood pressure was measured at the brachial artery by sphygmomanometry. Oxygen saturation was monitored with a pulse oximeter. Breath by breath gas analysis was performed with an AE280 instrument (Minato Medical Science, Osaka, Japan) connected to a personal computer running analysing software. ${ }^{21}$ The ratio of change in oxygen uptake to change in work rate $\left(\Delta \dot{\mathrm{V}}_{2} / \Delta \mathrm{W}\right.$ ratio $)$ was calculated as the slope of oxygen consumption per unit workload from one minute after the start of load addition until $85 \%$ of maximum $\dot{\mathrm{V}}_{2}$. Exercise capacity was evaluated by peak $\dot{\mathrm{V}}_{\mathrm{O}_{2}}$, which was defined as the value of averaged data during the final 15 seconds of exercise. The oxygen pulse, an index of stroke volume during exercise, was calculated by dividing $\dot{\mathrm{V}}_{2}$ by heart rate. Ventilatory efficiency on exercise was represented by the $\dot{V}_{\mathrm{E}}-\dot{\mathrm{V}}_{\mathrm{CO}_{2}}$ slope, where $\dot{V}_{E}$ is the expiratory minute volume. This was determined as the linear regression slope of $\dot{\mathrm{V}}_{\mathrm{E}}$ and $\dot{\mathrm{V}}_{\mathrm{CO}_{2}}$ from the start of exercise until the RC point (the time up until which ventilation is stimulated by $\mathrm{CO}_{2}$ output and end tidal $\mathrm{CO}_{2}$ tension begins to decrease). ${ }^{15}$

\section{Statistical analysis}

All data are expressed as mean (SEM) unless otherwise indicated. Comparisons of variables between two groups were made by Fisher's exact test or Student's unpaired $t$ test. Changes in variables during treatment with beraprost were analysed with the paired Student $t$ test. Correlation coefficients between exercise indices and pulmonary vascular resistance were calculated by linear regression analysis. A probability value of $p<0.05$ was considered significant. 
Table 2 Changes in exercise performance during beraprost sodium treatment in patients with pulmonary hypertension

\begin{tabular}{|c|c|c|c|}
\hline Variable & Baseline & BPS treatment & $p$ Value \\
\hline $\begin{array}{l}\text { Peak workload }(\mathrm{W}) \\
\text { Heart rate (beats/min) }\end{array}$ & $87(4)$ & $97(5)$ & $<0.001$ \\
\hline Rest & $82(2)$ & $80(3)$ & NS \\
\hline Peak & $147(4)$ & $152(4)$ & NS \\
\hline \multicolumn{4}{|l|}{$\mathrm{SAP}(\mathrm{mm} \mathrm{Hg})$} \\
\hline Rest & $125(4)$ & $124(4)$ & NS \\
\hline Peak & $162(6)$ & $171(6)$ & NS \\
\hline \multicolumn{4}{|l|}{$\mathrm{SaO}_{2}(\%)$} \\
\hline Rest & $97(1)$ & $97(1)$ & NS \\
\hline Peak & $92(1)$ & $91(1)$ & NS \\
\hline Peak Borg score (D/L) & $18 / 17$ & $18 / 18$ & NS \\
\hline Peak $\mathrm{V}_{2}(\mathrm{ml} / \mathrm{kg} / \mathrm{min})$ & $14.9(0.7)$ & $16.8(0.7)$ & $<0.001$ \\
\hline$\Delta \dot{\mathrm{V}}_{2} / \Delta \mathrm{W}$ ratio $(\mathrm{ml} / \mathrm{kg} / \mathrm{min} / \mathrm{W})$ & $6.6(0.3)$ & $7.4(0.3)$ & $<0.01$ \\
\hline Oxygen pulse (ml/beat) & $6.0(0.3)$ & $6.6(0.3)$ & $<0.001$ \\
\hline Maximum $\dot{V}_{E}(\mathrm{l} / \mathrm{min})$ & $49(3)$ & $52(3)$ & NS \\
\hline$\dot{\mathrm{V}} \mathrm{E}-\mathrm{V}_{\mathrm{CO}}$ slope & $42(2)$ & $37(1)$ & $<0.001$ \\
\hline Peak $R Q$ & $1.27(0.03)$ & $1.26(0.03)$ & NS \\
\hline
\end{tabular}

Data are mean (SEM)

BPS, beraprost sodium; peak Borg score (D/L), Borg score at peak exercise (dyspnoea/leg fatigue); $R Q$, respiratory quotient; $\mathrm{SaO}_{2}$, arterial oxygen saturation; $\mathrm{SAP}$, systolic arterial pressure; $\mathrm{V}_{\mathrm{E}}$, minute ventilation; $\dot{\mathrm{V}} \mathrm{E}-\dot{\mathrm{V}} \mathrm{CO}_{2}$ slope, slope of regression line of relation between $\mathrm{V} E$ and $\dot{\mathrm{V}}_{2} ; \Delta \mathrm{VO}_{2} / \Delta \mathrm{W}$ ratio, $\dot{\mathrm{V}}_{2}$ increase pe unit workload.

\section{RESULTS}

\section{Baseline exercise capacity and haemodynamic} variables

Nine patients (30\%) were classified as NYHA functional class II, and $21(70 \%)$ as class III. Baseline peak workload and peak $\dot{\mathrm{V}}_{2}$ in patients with pulmonary hypertension were significantly lower than the normal values, which were determined from pooled data of 20 age matched healthy subjects (peak workload, 87 (4) $v 147$ (7) W; peak $\dot{\mathrm{V}}_{\mathrm{O}_{2}}, 14.9$ (0.7) $v 28.9$ (l.1) $\mathrm{ml} / \mathrm{kg} / \mathrm{min} ; \mathrm{p}<0.001$, respectively). Baseline $\dot{\mathrm{V}}_{\mathrm{E}}-\dot{\mathrm{V}}_{\mathrm{CO}_{2}}$ slope was notably higher in patients with pulmonary

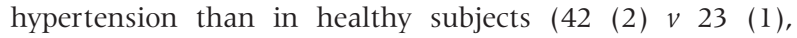
$\mathrm{p}<0.001)$, suggesting exaggerated ventilatory response to exercise in such patients. Baseline peak $\dot{\mathrm{V}}_{2}$ was negatively correlated with pulmonary vascular resistance $(r=-0.49$, $\mathrm{p}<0.01$ ), while the $\dot{\mathrm{V}}_{\mathrm{E}}-\dot{\mathrm{V}}_{\mathrm{CO}_{2}}$ slope was positively correlated with pulmonary vascular resistance $(r=0.66, \mathrm{p}<0.001)$.

\section{Effects of beraprost treatment on exercise capacity}

Following oral administration of beraprost, NYHA functional class improved significantly in 16 patients, worsened in two, and was unchanged in 12. Consequently, NYHA functional class in the beraprost group improved from $2.7(0.1)$ to 2.2 (0.1) $(\mathrm{p}<0.05)$. Oral administration of beraprost did not alter heart rate or blood pressure, either at rest or at peak exercise (table 2).

No significant changes in arterial oxygen saturation were observed during beraprost treatment, either at rest or at peak exercise. In contrast, beraprost increased peak workload in the patients with pulmonary hypertension (from 87 (4) to 97 (5) W; p < 0.001, fig l), although the respiratory quotient, an index of exercise effort, was not significantly altered (table 2 ). In addition, beraprost increased peak $\dot{\mathrm{V}}_{2}$ in the whole cohort of patients with pulmonary hypertension (from $14.9(0.7)$ to $16.8(0.7) \mathrm{ml} / \mathrm{kg} / \mathrm{min}, \mathrm{p}<0.001$, fig 2). Beraprost also increased the oxygen pulse, an index of stroke volume, and the $\Delta \dot{\mathrm{V}}_{2} / \Delta \mathrm{W}$ ratio (table 2). Oral administration of beraprost decreased the $\dot{V}_{\mathrm{E}}-\dot{\mathrm{V}}_{\mathrm{CO}_{2}}$ slope from 42 (2) to 37 (1) (p < 0.001 , fig 3$)$. These variables remained unchanged in patients who did not receive beraprost treatment (peak workload, 99 (11) to 101 (10) W; peak $\dot{\mathrm{V}}_{\mathrm{O}_{2}}, 18.4(2.2)$ to $18.6(2.2) \mathrm{ml} / \mathrm{kg} / \mathrm{min}$; $\dot{\mathrm{V}}_{\mathrm{E}}-\dot{\mathrm{V}}_{\mathrm{CO}_{2}}$ slope, 38 (3) to $\left.37(3), \mathrm{NS}\right)$.
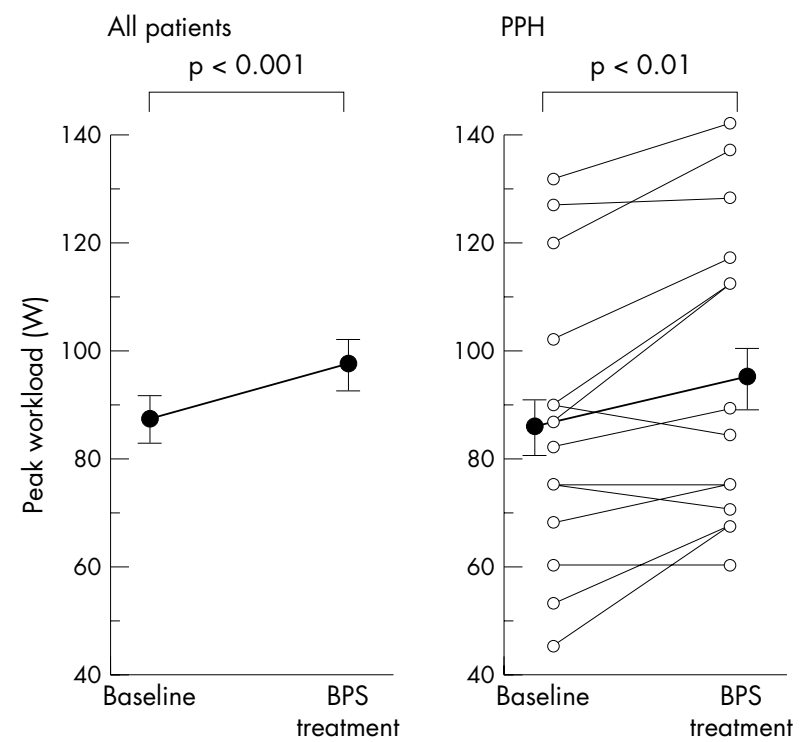

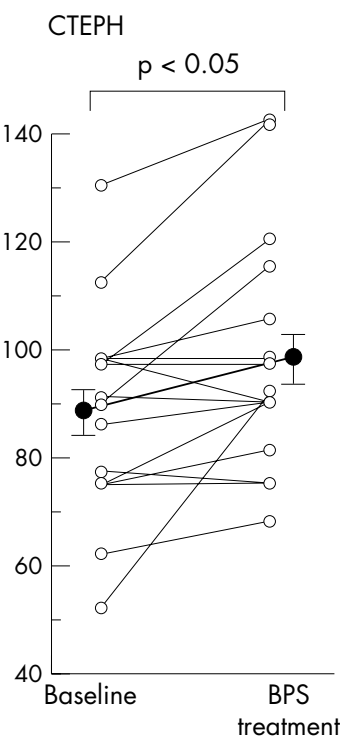

Figure 1 Changes in peak workload during oral administration of beraprost in patients with primary pulmonary hypertension (PPH) and chronic thromboembolic pulmonary hypertension (CTEPH). Data are means, error bars $=$ SEM 

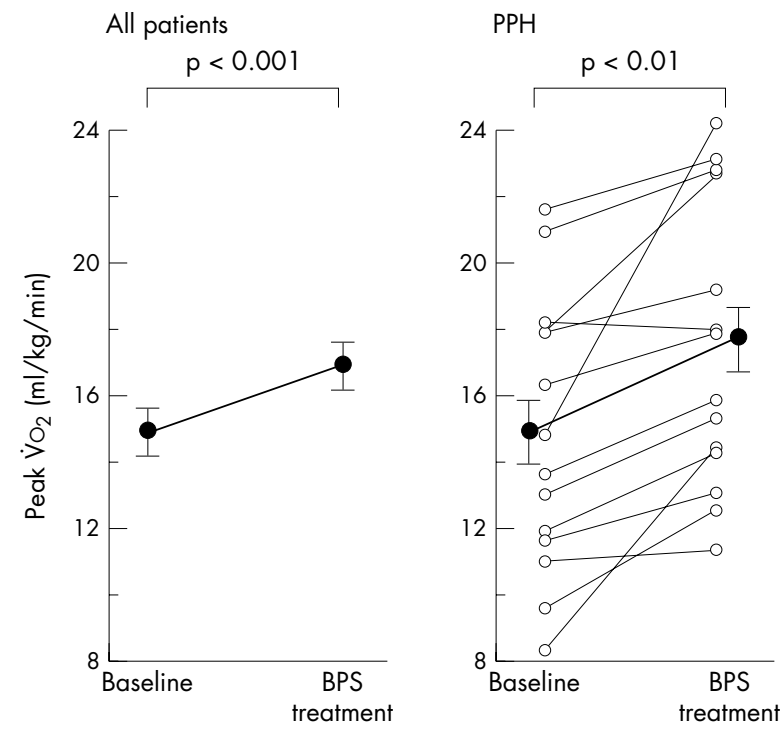

\section{Exercise responses in primary and chronic} thromboembolic pulmonary hypertension

Beraprost increased peak workload in patients with primary pulmonary hypertension from $86(7)$ to 95 (8) W (p < 0.01 , fig 1), and in patients with chronic thromboembolic pulmonary hypertension from 88 (5) to 98 (6) W (p < 0.05). Beraprost caused an $18 \%$ increase in peak $\dot{\mathrm{V}}_{2}$ in patients with primary pulmonary hypertension (from 14.8 (1.2) to 17.4 (1.2) $\mathrm{ml} / \mathrm{kg} / \mathrm{min} ; \mathrm{p}<0.01$, fig 2 ), and a $9 \%$ increase in patients with chronic thromboembolic pulmonary hypertension (from $15.0(0.9)$ to $16.4(0.8) \mathrm{ml} / \mathrm{kg} / \mathrm{min} ; \mathrm{p}<0.05)$. Treatment with beraprost resulted in a $16 \%$ decrease in the $\dot{\mathrm{V}}_{\mathrm{E}}-\dot{\mathrm{V}}_{\mathrm{CO}_{2}}$ slope in patients with primary pulmonary hypertension (from 43 (3) to $36(2) ; p<0.01$, fig 3), and a 7\% decrease in patients with chronic thromboembolic pulmonary hypertension (from 41 (3) to 38 (2); p < 0.05). However, these changes did not differ significantly between patients with primary pulmonary hypertension and those with chronic thromboembolic pulmonary hypertension.

\section{DISCUSSION}

In this study we showed first, that baseline peak $\dot{\mathrm{V}}_{2}$ was decreased and the $\dot{\mathrm{V}}_{\mathrm{E}}-\dot{\mathrm{V}}_{\mathrm{CO}_{2}}$ slope increased-with an increase
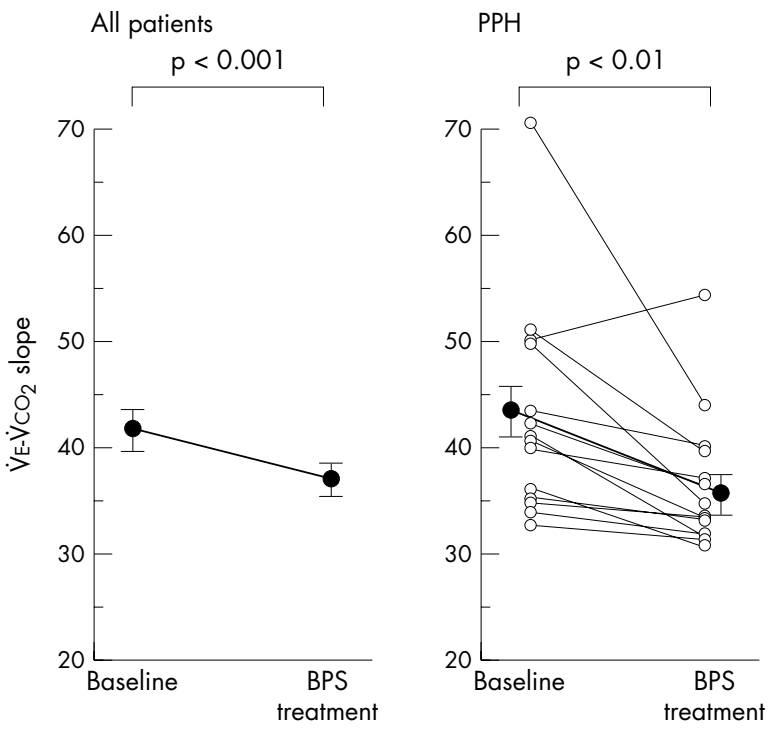

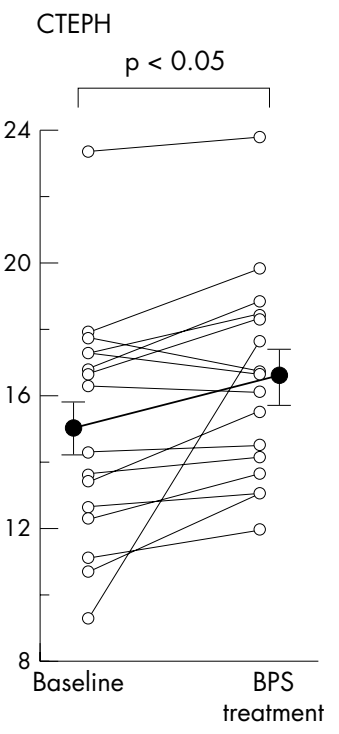

Figure 2 Changes in peak oxygen consumption (peak $\dot{\mathrm{V}}_{2}$ ) during oral administration of beraprost in patients with primary pulmonary hypertension (PPH) and chronic thromboembolic pulmonary hypertension (CTEPH). Data are means, error bars $=$ SEM

in pulmonary vascular resistance-in patients with precapillary pulmonary hypertension; second, that oral administration of beraprost resulted in an increase in peak workload and peak $\dot{\mathrm{V}}_{2}$, and a decrease in the $\dot{\mathrm{V}}_{\mathrm{E}}-\dot{\mathrm{V}}_{\mathrm{CO}_{2}}$ slope; and third, that there was no significant difference in responses of these variables to beraprost treatment between patients with primary pulmonary hypertension and those with chronic thromboembolic pulmonary hypertension. These results suggest that oral administration of beraprost may improve exercise capacity and ventilatory efficiency in both groups of patients.

Recently, the continuous intravenous administration of epoprostenol (prostacyclin) has been shown to cause pronounced lowering of pulmonary vascular resistance and improved exercise capacity in patients with either primary or secondary pulmonary hypertension..$^{5-8} 22$ However, epoprostenol is rapidly metabolised and hence needs to be given by continuous intravenous infusion. This raises issues concerned with quality of life and cost effectiveness. In contrast, beraprost can be given orally because of its prolonged activity in the body. ${ }^{10}{ }^{11}$ Beraprost has been shown to decrease pulmonary vascular resistance in patients with primary pulmonary hypertension. ${ }^{12-14}$ However, the effects of oral beraprost on exercise capacity-which is one of the most sensitive and

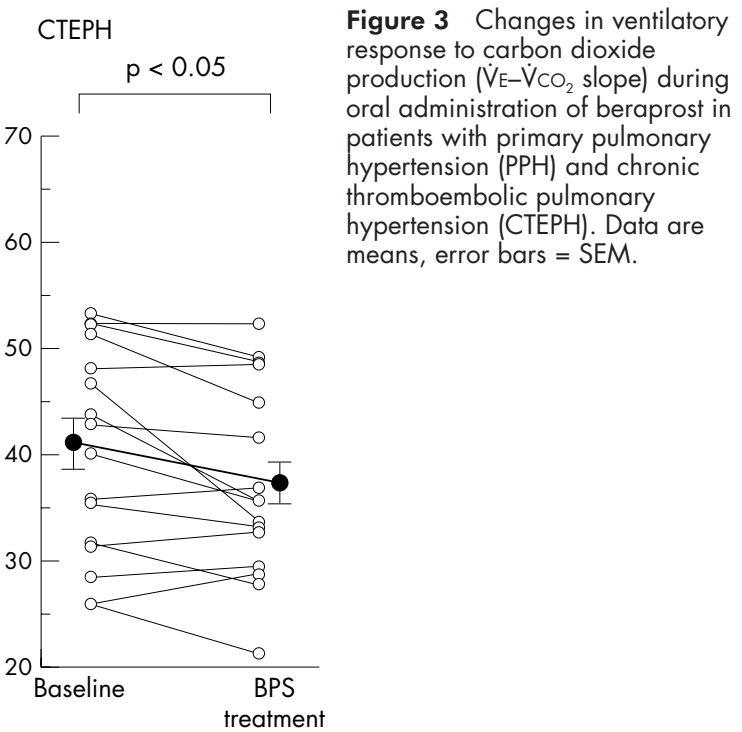


objective indices of functional impairment from pulmonary hypertension-remain unknown.

In this study, we showed that the oral administration of beraprost improved exercise capacity in patients with precapillary pulmonary hypertension (primary pulmonary hypertension and chronic thromboembolic pulmonary hypertension), as indicated by the increases in peak workload and peak $\dot{\mathrm{V}}_{2}$, without significant change in the respiratory quotient. Peak $\dot{\mathrm{V}}_{2}$ is determined from the maximum cardiac output during exercise, the potential for oxygen extraction by the exercising muscle, and the ventilatory capacity. ${ }^{23}$ The decrease in peak $\dot{\mathrm{V}}_{2}$ associated with the degree of pulmonary hypertension may reflect insufficient oxygen delivery to the body during exercise, caused at least in part by an inadequate increase in cardiac output under conditions of severe pulmonary hypertension. In the present study, beraprost treatment significantly increased peak $\dot{\mathrm{V}}_{\mathrm{O}_{2}}$, the $\Delta \dot{\mathrm{V}}_{2} / \Delta \mathrm{W}$ ratio, and the oxygen pulse - an index of stroke volume during exercise. Recently, we and others have shown that long term treatment with beraprost increases cardiac output and decreases pulmonary vascular resistance at rest, although the haemodynamic responses to beraprost are relatively small compared with those to intravenous epoprostenol. ${ }^{12-14}$ These results suggest that beraprost may improve cardiac performance during exercise by causing pulmonary artery dilatation, resulting in an improvement in exercise capacity.

Previous studies have also shown that oral beraprost treatment inhibits the development of monocrotaline induced pulmonary hypertension and reduces medial thickness of the pulmonary artery in rats. ${ }^{24}$ Thus it is also possible that the increase in exercise capacity during long term treatment with beraprost may partly reflect an improvement in pulmonary vascular remodelling in patients with pulmonary hypertension.

The increase in the $\dot{\mathrm{V}}_{\mathrm{E}}-\dot{\mathrm{V}}_{\mathrm{CO}_{2}}$ slope is taken to reflect a reduced ventilatory efficiency of gas exchange, which is associated mainly with increased physiological dead space and a decrease in the $\mathrm{PaCO}_{2}$ regulatory set point. ${ }^{17-19}$ In the present study, the $\dot{\mathrm{V}} \mathrm{E}-\dot{\mathrm{V}}_{\mathrm{CO}_{2}}$ slope was strongly correlated with the degree of pulmonary vascular resistance, suggesting the presence of exaggerated ventilatory response to exercise (impaired ventilatory efficiency) in patients with pulmonary hypertension. Oral administration of beraprost improved ventilatory efficiency in patients with pulmonary hypertension, as indicated by a significant decrease in the $\dot{\mathrm{V}}_{\mathrm{E}}-\dot{\mathrm{V}}_{\mathrm{CO}_{2}}$ slope. It is possible that the decrease in the $\dot{\mathrm{V}}_{\mathrm{E}}-\dot{\mathrm{V}}_{\mathrm{CO}_{2}}$ slope may be attributable to the pulmonary vasodilator effect of beraprost, leading to an improvement in cardiac output and a decrease in physiological dead space during exercise. It should be noted that beraprost did not alter arterial oxygen saturation either at rest or at peak exercise. In addition, beraprost did not affect blood pressure or heart rate either at rest or at peak exercise, although a problem with any vasodilator in pulmonary hypertension is considered to be the potential complication of systemic hypotension. Thus oral administration of beraprost may be beneficial in patients with precapillary pulmonary hypertension.

Although we have previously reported the beneficial effect of oral beraprost in patients with primary pulmonary hypertension, ${ }^{12}{ }^{14}$ whether it is similarly effective in patients with chronic thromboembolic pulmonary hypertension remains unknown. Unlike primary pulmonary hypertension, chronic thromboembolic pulmonary hypertension is considered to be the result of chronic obstruction of the pulmonary arteries by thrombus. ${ }^{23}$ Nevertheless, administration of beraprost significantly increased peak $\dot{\mathrm{V}}_{2}$ and decreased the $\dot{\mathrm{V}}_{\mathrm{E}}-\dot{\mathrm{V}}_{\mathrm{CO}_{2}}$ slope in our patients with chronic thromboembolic pulmonary hypertension as well as in those with primary pulmonary hypertension. Recently, the intravenous administration of epoprostenol (prostacyclin) has been shown to decrease pulmonary vascular resistance in patients with chronic thromboembolic pulmonary hypertension. ${ }^{25}$ From these findings it appears that-as in primary pulmonary hypertension-pulmonary vasoconstriction may be at least partially responsible for the pulmonary hypertension of chronic thromboembolism, and so a reduction of this vasoconstriction by beraprost may decrease pulmonary vascular resistance, leading to improvement in exercise capacity and ventilatory efficiency in such patients. Further investigations are needed to clarify the mechanisms responsible for the improvement in exercise capacity and ventilatory efficiency during beraprost treatment. In contrast to major vessel chronic thromboembolic pulmonary hypertension, which may be surgically corrected, peripheral chronic thromboembolic pulmonary hypertension has no surgical option. ${ }^{9}$ Oral beraprost may thus be an alternative treatment approach in this condition.

\section{Study limitations}

Firstly, patients with the most severe forms of pulmonary hypertension were excluded from this study protocol because they were not eligible for maximum cardiopulmonary exercise testing in the judgement of their attending physicians. Our study may therefore include milder forms of pulmonary hypertension than earlier studies. ${ }^{86}$ The effects of oral beraprost in the most severe forms of primary pulmonary hypertension and chronic thromboembolic pulmonary hypertension remain unknown.

Secondly, this study was not a controlled trial. The patients without beraprost treatment were neither randomised nor placebo controlled, and the severity of disease in that group was different from that in the beraprost treatment group, which may have biased the comparison. Nonetheless, we found no significant improvement in exercise performance indices in patients not given beraprost, indicating there were no training effects in the study interval.

Thirdly, the time span from baseline to the test under treatment was variable, which may bias the comparison. Nevertheless, the mean follow up period was three months, which is an appropriate time span accepted by earlier studies. ${ }^{87}$ In addition, treatment duration did not correlate significantly with changes in exercise performance (data not shown).

Finally, two patients were not retested because they were referred to local institutions. However, this small drop out rate did not change the significance of the results and conclusions.

\section{Conclusions}

Oral administration of beraprost may improve exercise capacity and ventilatory efficiency both in patients with primary pulmonary hypertension and in those with chronic thromboembolic pulmonary hypertension.

\section{ACKNOWLEDGEMENTS}

We thank Keiko Tanegashima for her technical assistance. This work was supported by the Japan Intractable Diseases Research Foundation, the Uehara Memorial Foundation, and a grant from the Japan Cardiovascular Research Foundation.

\footnotetext{
Authors' affiliations

N Nagaya, Y Shimizu, T Satoh, H Oya, S Kyotani, F Sakamaki, N Sato, N Nakanishi, K Miyatake, Division of Cardiology, Department of Medicine, National Cardiovascular Centre, Osaka, Japan M Uematsu, Department of Internal Medicine, Osaka Seamen's Insurance Hospital, Osaka, Japan

\section{REFERENCES}

1 Rich S, Dantzker DR, Ayres SM, et al. Primary pulmonary hypertension: a national prospective study. Ann Intern Med 1987;107:216-23.

2 Viner SM, Bagg BR, Auger WR, et al. The management of pulmonary hypertension secondary to chronic thromboembolic disease. Prog Cardiovasc Dis 1994;37:79-92

3 Goldhaber SZ. Pulmonary embolism. N Engl J Med 1998;339:93-104

4 Janicki JS, Weber KT, Likoff $M$, et al. The pressure-flow response of the pulmonary circulation in patients with heart failure and pulmonary vascular disease. Circulation 1985;72:1270-8.
} 
5 Higenbottam TW, Wheeldon D, Wells FC, et al. Long-term treatment of primary pulmonary hypertension with continuous intravenous epoprostenol (prostacyclin). Lancet 1984;i:1046-7.

6 Rubin LJ, Mendoza J, Hood M, et al. Treatment of primary pulmonary hypertension with continuous intravenous prostacyclin (epoprostenol): results of a randomized trial. Ann Intern Med 1990;1 12:485-91.

7 Barst RJ, Rubin LJ, Long WA, et al. A comparison of continuous intravenous epoprostenol (prostacyclin) with conventional therapy for primary pulmonary hypertension. N Engl J Med 1996;334:296-301.

8 McLaughlin VV, Genthner DE, Panella MM, et al. Reduction in pulmonary vascular resistance with long-term epoprostenol (prostacyclin) therapy in primary pulmonary hypertension. N Engl J Med 1998;338:273-7.

9 Moser KM, Auger WR, Fedullo PF. Chronic major-vessel thromboembolic pulmonary hypertension. Circulation 1990;81:1735-43.

$10 \mathrm{Sim}$ AK, McCraw AP, Cleland ME, et al. Effects of a stable prostacyclin analogue on platelet function and experimentally-induced thrombosis in the microcirculation. Arzneimittelforschung 1985;35:1816-18.

11 Murata T, Murai T, Kanai T, et al. General pharmacology of beraprost sodium, second communication: effects on the autonomic, cardiovascular and gastrointestinal systems, and other effects. Arzneimittelforschung 1989;39:867-76.

12 Okano Y, Yoshioka A, Shimouchi A, et al. Orally active prostacyclin analogue in primary pulmonary hypertension. Lancet 1997;349:1365.

13 Ichida F, Uese K, Tsubata S, et al. Additive effect of beraprost on pulmonary vasodilation by inhaled nitric oxide in children with pulmonary hypertension. Am J Cardiol 1997;80:662-4.

14 Nagaya $N$, Uematsu $M$, Okano $Y$, et al. Effect of orally active prostacyclin analogue on survival of outpatients with primary pulmonary hypertension. J Am Coll Cardiol 1999;34:1188-92.

15 Wensel R, Opitz CF, Ewert R, et al. Effects of iloprost inhalation on exercise capacity and ventilatory efficiency in patients with primary pulmonary hypertension. Circulation 2000;101:2388-92.

16 Janicki JS, Weber KT, Likoff M, et al. Exercise testing to evaluate patients with pulmonary vascular disease. Am Rev Respir Dis 1984; 129:S93-5.

17 D'Alonzo GE, Gianotti LA, Pohil RL, et al. Comparison of progressive exercise performance of normal subjects and patients with primary pulmonary hypertension. Chest 1987;92:57-62

18 Ting $\mathbf{H}$, Sun XG, Chuang ML, et al. A noninvasive assessment of pulmonary perfusion abnormality in patients with primary pulmonary hypertension. Chest 2001;119:824-32.

19 Sun XG, Hansen JE, Oudiz RJ, et al. Exercise pathophysiology in patients with primary pulmonary hypertension. Circulation 2001;104:429-35.

20 Auger WR, Fedullo PF, Moser KM, et al. Chronic major-vessel thromboembolic pulmonary artery obstruction: appearance at angiography. Radiology 1992;182:393-8.

21 Miyamoto S, Nagaya N, Satoh T, et al. Clinical correlates and prognostic significance of six-minute walk test in patients with primary pulmonary hypertension: comparison with cardiopulmonary exercise testing. Am J Respir Crit Care Med 2000;161:487-92.

22 Badesch DB, Tapson VF, McGoon MD, et al. Continuous intravenous epoprostenol for pulmonary hypertension due to the scleroderma spectrum of disease. A randomized, controlled trial. Ann Intern Med 2000;132:425-34

23 Anderson P, Saltin B. Maximal perfusion of skeletal muscle in man. J Appl Physiol 1985;366:233-49.

24 Yuki H, Sato S, Arisaka Y, et al. Orally administered beraprost sodium inhibits pulmonary hypertension induced by monocrotaline in rats. Tohoku J Exp Med 1994;173:371-5.

25 Higenbottam T, Butt AY, McMahon A, et al. Long-term intravenous prostaglandin (epoprostenol or iloprost) for treatment of severe pulmonary hypertension. Heart 1998;80:151-5.

26 Nagaya N, Nishikimi T, Uematsu T, et al. Plasma brain natriuretic peptide as a prognostic indicator in patients with primary pulmonary hypertension. Circulation 2000;102:865-70

27 Badesch DB, Tapson VF, McGoon MD, et al. Continuous intravenous epoprostenol for pulmonary hypertension due to the scleroderma spectrum of disease. A randomized, controlled trial. Ann Intern Med $2000 ; 132: 425-34$

\section{WEB TOP TEN}

\section{www.heartinl.com}

These articles scored the most hits on

Heart's website during January 2002

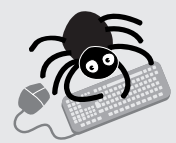

1 Hypertrophic cardiomyopathy: management, risk stratification, and prevention of sudden death WJ McKenna, ER Behr

February 2002;87: 169-76. (Education in Heart)

2 Inflammatory gene polymorphisms and ischaemic heart disease: review of population association studies

F Andreotti, I Porto, F Crea, A Maseri

February 2002;87:107-12. (Reviews)

3 Joint British recommendations on prevention of coronary heart disease in clinical practice

Dec 1998;80(suppl 2): 1-29.

4 The "no-reflow" phenomenon: basic science and clinical correlates

$T$ Reffelmann, RA Kloner

February 2002;87:162-8. (Education in Heart)

5 Timing of mitral valve surgery

M Enriquez-Sarano

January 2002;87:79-85. (Education in Heart)

6 Cirrhotic cardiomyopathy: a pathophysiological review of circulatory dysfunction in liver disease $S$ Moller, JH Henriksen January 2002;87:9-15. (Reviews)

7 "Diastolic heart failure" or heart failure caused by subtle left ventricular systolic dysfunction? MC Petrie, L Caruana, C Berry, JJV McMurray

January 2002;87:29-31. (Cardiovascular medicine)

\section{Cardiac transplantation}

MC Deng

February 2002;87:177-84. (Education in Heart)

9 Introducing a new role for BNP: as a general indicator of cardiac structural disease rather than a specific indicator of systolic dysfunction only A D Struthers

February 2002;87:97-8. (Editorials)

10 Are angiotensin II receptor blockers indicated in chronic heart failure?

M Komajda

January 2002;87:1-2. (Editorials)

Visit the Heart website for hyperlinks to these articles, by clicking on "Top 10 papers"

www.heartinl.com 